\title{
165. Inoculation of Sarcoma 180 to Mice which Acquired a Resistibility against Ehrlich Ascites Tumor
}

\author{
By Kazuyuki MaEKaWA and Masahisa Kushibe \\ Faculty of Agriculture, Kyushu University, and Faculty of Agriculture, \\ Ehime University
}

(Comm. by Yuzuru OKudA, M. J. A., Oct. 13, 1969)

It was recently elucidated that, by applying at certain intervals 2 injections of Ehrlich ascites tumor cells attenuated appropriately by means of MA: Ehr.RNA, thereafter the challenge inoculation with $10^{5}$ tumor cells did not develop any tumor. ${ }^{1)-3)}$ Into the mice which acquired a resistibility against Ehrlich ascites tumor, sarcoma 180, one of a type of solid tumors, was inoculated within 3-6 months after the challenge inoculation of Ehrlich ascites tumor cells. The results showed that the mice pretreated were completely resistant to sarcoma 180.

Experimentals. Materials and methods. The preparation and purification of the Ehrlich RNA fraction (Ehr.RNA) were carried out as described previously.4) Methylated bovine serum albumin (MA) prepared by the method of Mandell et al.5) was dissolved in water and then made $0.85 \% \mathrm{NaCl}$ solution by adding $\mathrm{NaCl}$. The preparation of MA: Ehr.RNA-complex was also carried out according to the method reported already.

The mice (ddT) rescued from the challenge inoculation of tumor cells by means of repeated pretreatment of MA: Ehr.RNA were used. According to the time which elapsed after final inoculation of tumor cells, the mice were divided into 3 groups. Intact mice were used as a control. The maintenance of mice was fulfilled at $25^{\circ} \pm 2^{\circ} \mathrm{C}$, and $50-60 \%$ humidity.

Results and discussion. In 3-6 months after the challenge inoculation to the pretreated mice, $10^{5}$ cells of sarcoma 180 tumor were inoculated into the mice. The results obtained are shown in Table I. Namely, none of the treated mice became ill. The surviving mice were dissected after 6 months to study the aspects of tumor cells. However there were none.

It was thought that an ability to produce certain anti-tumor factors in the bodies of mice was elicited by means of treatment with attenuated Ehrlich tumor cells. The ability elicited by such a procedure could also completely inhibit the incidence of sarcoma 180 . These facts may suggest some important conclusions. On the one 
Table I. Inoculation of sarcoma 180 to mice which acquired a resistibility against Ehrlich ascites tumor

\begin{tabular}{c|c|c|c}
\hline Groups & $\begin{array}{c}\text { Days elapsed after challenge } \\
\text { inoculation with Ehrlich } \\
\text { ascites tumor cells }\end{array}$ & No. of mice & S/T* \\
\hline A & 3 month & 4 & $4 / 4$ \\
B & $4,$, & 5 & $5 / 5$ \\
C & $6,$, & 5 & $5 / 5$ \\
\hline Control & & 6 & $0 / 6$ \\
\hline
\end{tabular}

* No. of survivors/No. of total.

hand, if the inhibitory ability were perticipated by something like interferon, since the life-time of interferon in the body is rather short, the inhibitory ability must have been produced continuously over a long time.

On the other hand, since the target of interferon is virus, and the interferon induced by an organism is equally effective on other viruses of the same organism, if the anti-tumor effect were ascribable to some interferon, an inference that Ehrlich ascites tumor and also sarcoma 180 of mice might be brought about by viruses will be drawn.

As a matter of fact, any evidence that this effective factor is interferon is not present. Therefore, in these experiments a quite different mechanism might have been taking part.

Nevertheless, the fact that the treating methods are effective against Ehrlich ascites tumor and sarcoma 180 may be interesting from the view of therapy.

Acknowledgement. The experiments on sarcoma 180 were carried out by Dr. K. Aikawa and a collaborator in the pharmacological laboratory of Nikken Kagaku, Co. (Tokyo). We are thankfu lto them.

\section{References}

1) K. Maekawa and M. Kushibe: Proc. Japan Acad., 45, 298 (1969).

2) M. Kushibe, O. Ochi, Y. Kuwabara, and K. Maekawa: Proc. Japan Acad., 44, 558 (1968).

3) K. Maekawa and M. Kushibe: 6th Intern. Congr. Chemotherapy (Tokyo), Aug. 10-15 (1969), Abst. of papers, p. 329.

4) - : Proc. Japan Acad., 43, 224 (1967).

5) J. D. Mandell and A. D. Hershey: Anal. Biochem., 1, 66 (1960). 